\title{
An evaluation of automatic coding of surgical pathology reports
}

\author{
EDWARD C. COLES AND GERARD SLAVIN \\ From the Division of Computing and Statistics and the Department of Histopathology, Northwick Park \\ Hospital and the Clinical Research Centre, Watford Road, Harrow, Middlesex
}

SYNOPSIS The use of the Systematised Nomenclature of Pathology as the basis of an indexing system to histopathological data is outlined. Two computer programs which perform the task of producing codes from free English summaries are compared. It is concluded that a simple system has a great deal to offer the pathologist who is prepared to accept a set of constraints.

Many histopathologists find that a system of coding and indexing the salient details of their reports provides a useful method for reviewing past material. The ability to do this accurately is helpful for reviewing difficult cases, for teaching, and for research. The Systematised Nomenclature of Pathology (SNOP) (College of American Pathologists, 1965) is a comprehensive and sophisticated system which can be used for these purposes (Pratt and Thomas, 1966). It provides separate sets of four-digit codes to describe four aspects of the specimen, namely Topography, Morphology, Aetiology, and Function (T, M, E, F). These codes can be used as the basis of an indexing system for copies of reports, slides, photographs, and museum specimens, both for card files and for computer-based systems. Moreover the rapidity of computers will allow the daily search of files to review previous diagnoses in patients with material currently under examination in the laboratory.

Several centres in this country are now establishing computer-based files of surgical pathology diagnoses (Williams, 1974, personal communication). In the Birmingham Region, pathology departments of different hospitals are combining to form a subregional file (Curran and Codling, 1973).

One of the difficulties of preparing data for entry into the computer file is that of recording the appropriate code. Looking up phrases in a code-book is tedious, time-consuming, and prone to error (Dinwoodie and Howell, 1973). We are therefore attempting to produce a system in which encoding follows automatically from an English summary typed on the report. The use of an English summary obviates the need for manual look-up of the codes, Received for publication 2 December 1975 and the data may be prepared for entry to the computer system as a byproduct of normal office routines. This paper reports an evaluation of Pratt's computer system of automatic encoding of histopathology phrases (Pratt, 1973) and our own experience with a simpler pilot system based on the ICL 1900 Series computers which are used by most Regional Health Authorities in the United Kingdom.

\section{Methods}

A strictly random selection of 1 in 70 of all surgical pathology reports for the period from September 1970, when Northwick Park Hospital opened, until the end of 1972 was obtained. This produced a total of 99 reports which were passed to a registrar in pathology with the request that they should be summarized in terse English sentences. As well as the registrar's summaries one of us (GS) (a) produced an initial set of summaries for testing against Dr Pratt's system, (b) performed a manual encoding process by looking up the SNOP volume, and (c) in the light of three months' experience with the Northwick Park pilot encoder, produced a second set of summaries for comparison with the first set when submitted to the Northwick Park encoder.

The form of the registrar's summary for each specimen was usually a single terse free English sentence which specified the topography as the anatomical site or the tissue, and the pathology. Sometimes more than one topography or pathology was mentioned in a single sentence. The form of the consultant's summaries was one or more pairs of phrases, the first of which specified the topography and the second one the morphological changes. The second set of consultant's summaries differed 
from the first only in matters of detail. These details reflect the need to match the idiosyncrasies of the nomenclature and more particularly those of the Northwick Park encoder which requires separate phrases for the different fields of the nomenclature (Topography, Morphology, Aetiology, and Function) as it deals with each field in isolation.

The registrar's and the consultant's first summaries usually produced different phrases from the same report, and the consultant's second summary, which aimed at exact matching with the SNOP phrases, sometimes differed again. Examples of these are given below.

These examples contain some of the minority of cases in which it was necessary to use more than one diagnostic summary statement per report. The registrar produced an average of 1.07 statements per case; the consultant on the first and second occasions produced 1.28 and 1.21 statements per case respectively. The registrar's and the consultant's first set of summary statements were run against the encoder used by the Laboratory of Pathology at the National Institutes of Health (NIH). The consultant's first and second sets of summary statements were run against the Northwick Park pilot encoder.

The aim of the encoding process is to achieve a correct match between the meaning of the phrases used in the diagnostic summary statements and the meaning of phrases in the nomenclature, so that the appropriate codes can be used for indexing. The NIH encoder goes to considerable lengths to achieve this in an analysis of a free English sentence (Pratt and Pacak, 1969), eg, by turning ovaries, which is not in SNOP, into left ovary and right ovary, which are in SNOP, and by turning adjectives into nouns and sometimes vice versa. It also attempts to match as much of each sentence as it can against the nomenclature. It may for example pick up two morphologies and three topographies and produce six topography-morphology pairs. This can lead to errors, eg, a sentence containing the words kidney and pelvic peritoneum led to the code for pelvic kidney being generated.

The Northwick Park pilot encoder takes a much more simple approach to the problem, looking for an exact letter-by-letter match between the phrase used and a phrase in the appropriate section of the $\frac{0}{5}$ nomenclature. It also requires that the phrases used음 are in the SNOP sequence of topography, morph- $\vec{F}$ ology, aetiology, and function-although all ex- $\frac{\rho}{+}$ cept the topography phrase may be omitted. For을 example, in the consultant's second summary of case $\frac{\bar{\sigma}}{\bar{n}}$ 4 above, topography, morphology, and function $\frac{\bar{\sigma}}{\sigma}$ phrases are given, the adjacent commas indicating $\stackrel{\mathbb{}}{\complement}$ to the computer that there is no aetiology phrase. is

In most of the nomenclature SNOP provides a $\vec{\circ}$ phrase for each code that has any meaning in the system. However, in the morphology section this is $\vec{\omega}$ not invariably true. In the part dealing with neo-? plasms not all possible alternatives of benign oro malignant, primary or metastatic are enumerated. 응 Instead a set of rules is supplied which specify the $-v$ meaning of the fourth digit of the codes and allow them to be modified accordingly. For example, this section contains the phrase squamous cell carcinoma음 and its code M8073 but not the phrase metastatic squamous cell carcinoma and its code M8076. Per- $\stackrel{\complement}{\complement}$ ceiving that this second phrase is a valid one and $\frac{}{<}$ changing M8073 to M8076 is a simple process for a $\vec{\varphi}$ human coder. To write a computer program to doō this is, however, a complex task, and the NIH en-D coder did not achieve the correct code in all such cases. The Northwick Park encoder does not yet $\bar{ᅳ}$ attempt to do this but instead it allows a numeric code rather than an English phrase to be entered $\stackrel{\square}{\square}$ directly in this circumstance. Thus, in order to enter $\Rightarrow$ metastatic carcinoma in bone the pathologist dic-을 tates: Bone, M8146.

\section{Results}

The results of encoding by the three methods are given in tables I to III. Correctness was judged by comparing the meaning given in SNOP for the codeso generated against the meaning of the phrase sub- $₹$ mitted. Only those statements in which there was a을 complete and accurate match were classified as cor- $\rightarrow$ rect.

Some of the statements submitted to the NIHN encoder were incorrectly coded and others were in-adequately coded. Examples of these are sub- 0 periosteal being coded to periosteum and the phrase

\begin{tabular}{|c|c|c|c|}
\hline Case & $\begin{array}{l}\text { Registrar's Summaries } \\
\text { (tested against NIH encoder) }\end{array}$ & $\begin{array}{l}\text { Consultant's First Summaries } \\
\text { (tested against NIH and NPH } \\
\text { encoders) }\end{array}$ & $\begin{array}{l}\text { Consultant's Second Summaries } \\
\text { (tested against NPH encoder) }\end{array}$ \\
\hline $\begin{array}{l}1 \\
2\end{array}$ & $\begin{array}{l}\text { Epidermoid cyst from neck. } \\
\text { Secretory phase endometrium. } \\
\text { Endocervical polyp. }\end{array}$ & $\begin{array}{l}\text { Skin of neck, epidermoid cyst. } \\
\text { Endometrium, secretory phase. } \\
\text { Endocervix, polyp. }\end{array}$ & $\begin{array}{l}\text { Skin of neck, epidermoid cyst. } \\
\text { Endometrium, secretory endo- } \\
\text { metrium. Endocervix, polyp. }\end{array}$ \\
\hline 3 & $\begin{array}{l}\text { Normal fallopian tube, } \\
\text { haemorrhagic cystic corpus } \\
\text { luteum. }\end{array}$ & $\begin{array}{l}\text { Fallopian tube, normal. } \\
\text { Corpus luteum, } \\
\text { haemorrhage. }\end{array}$ & $\begin{array}{l}\text { Fallopian tube, normal. } \\
\text { Ovary, cystic corpus luteum. }\end{array}$ \\
\hline 4 & $\begin{array}{l}\text { Alcoholic hepatitis and } \\
\text { micronodular cirrhosis. }\end{array}$ & $\begin{array}{l}\text { Liver, alcoholic hepatitis, } \\
\text { Liver, micronodular cirrhosis. }\end{array}$ & $\begin{array}{l}\text { Liver, hepatitis,, alcoholism. } \\
\text { Liver, cirrhosis,, alcoholism. }\end{array}$ \\
\hline
\end{tabular}




\begin{tabular}{|c|c|c|}
\hline & $\begin{array}{l}\text { Correctly } \\
\text { coded }\end{array}$ & $\begin{array}{l}\text { Incorrectly or } \\
\text { inadequately } \\
\text { coded }\end{array}$ \\
\hline $\begin{array}{l}\text { Registrar's summaries } \\
\text { Consultant's first summaries }\end{array}$ & $\begin{array}{l}83 \\
93 \cdot 7\end{array}$ & $\begin{array}{c}17 \\
6 \cdot 3\end{array}$ \\
\hline
\end{tabular}

Table I Percentage of diagnostic summary statements correctly coded by the NIH encoder

\begin{tabular}{lll}
\hline & $\begin{array}{l}\text { Correctly } \\
\text { coded }\end{array}$ & $\begin{array}{l}\text { Incorrectly } \\
\text { coded }\end{array}$ \\
\hline Consultant's first summaries & 93.7 & 6.3 \\
\hline
\end{tabular}

Table II Percentage of diagnostic summary statements correctly hand-coded by the consultant

\begin{tabular}{lll}
\hline & $\begin{array}{l}\text { Correctly } \\
\text { coded }\end{array}$ & Not coded \\
\hline $\begin{array}{l}\text { Consultant's first summaries } \\
\begin{array}{l}\text { Consultant's second } \\
\text { summaries }\end{array}\end{array}$ & 67.7 & 32.3 \\
\hline
\end{tabular}

Table III Percentage of diagnostic summary statements correctly coded by the pilot encoder at Northwick Park

'Two of the statements $(1.7 \%)$ are excluded from this total because phrases in them were known to require facilities not yet available in the Northwick Park encoder, so the code rather than the phrase was submitted (see text).

treated thyrotoxicosis with some lymphocytic infiltration not producing the topography code for thyroid.

It is interesting but not surprising to find that the pathologist made a number of errors when hand coding in the environment of a busy service laboratory. His error rate of $6.3 \%$ does, however, compare well with those of $12 \%$ and $17 \%$ quoted by Dinwoodie and Howell for general practice and hospital morbidity data. Four of the eight errors made appear to be transcription errors as the correct and incorrect codes differ by only a single digit.

The Northwick Park encoder is a much simpler program than the NIH encoder. It does very little in the way of making 'intelligent assumptions' about phrases which it cannot find in its dictionaries. This leads to the virtue that it has only once (subsequent to our tests) produced a code when it should strictly not have done so. When the encoder fails to find a phrase it looks for any English spelling constructions which it can change to the American form. Having made such a change it tries again. This process led to the mis-typing oendometrium being changed to endometrium, with a subsequent successful lookup. The last column of table III shows the proportion of statements in which the encoder failed to achieve a match between the phrase used and one in the appropriate dictionary, there being no incorrectly coded statements. Two diagnostic statements have been excluded from the last line of this table because the facility to enter codes instead of phrases was used to compensate for the known deficiency of the program in not coping with the word metastatic in morphology phrases.

\section{Discussion}

Histopathology data files have an important function both for improving individual patient care and as tools for the study of the masses of material which pass through busy departments. Most individual laboratories maintain files and these may vary in complexity from simple card indexes to sophisticated computer-based files which serve regions or subregions.

It is likely with the advent of more Regional and hospital computers that greater opportunities for computer-based files will become available to district general hospitals. These allow more sophisticated manipulation of the data than card files but are more demanding in input by the pathologist. At some point in the coding of diagnostic data there must be reference to the appropriate dictionary to find the code which must then be processed for entry to the computer, usually by punching into cards or paper tape. Manual lookup of the SNOP dictionary is tedious. This may be lessened by use of the Bench Synopsis (Royal College of Pathologists, 1975) but discussion with other pathologists confirms that this step inhibits many from starting such files. In addition, manual lookup involves errors of commission with transcription of wrong codes (Dinwoodie and Howell, 1973).

With these defects in mind we have begun to develop a system of automatic encoding of surgical pathology data which follows directly from the typing of the report. It has been central to our study that:

(1) the pathologist should have to do a minimum of dictionary lookup-recording the diagnosis by means of standard English SNOP phrases, preferably as part of the report; and

(2) data preparation should involve the typing of English phrases, the translation into numerical codes being automatic and internal within the computer system.

Smith and Melton (1964) described in outline a system for the preparation of data for the computer as a byproduct of office routines based on their own lexicon. Others have described attempts to translate free English reports directly into computer-coded format (Gaynon and Wong, 1972; Kayser and Höpker, 1973; Enlander, 1975). Pratt and Pacak (1969) evolved an elaborate syntactic analysis and coding of pathological reports based on SNOP, and 
at the outset of our study we became aware of the importance of this work. Their aim as computational linguists is the analysis of free English text, and the correct encoding rate $(83 \%)$ of submitted data is a significant achievement in that field. However, this figure is not acceptable to pathologists generating data files, and our experience suggests that some restriction of the English input format is needed to achieve adequate rates of correct encoding. Moreover Pratt's system is based on computer facilities far in excess of those available to British hospitals.

In the use of the Northwick Park pilot encoder it has been accepted that the English input must be in the T, M, E, F format and that the individual phrases in each field must exactly match those in the SNOP dictionary. In practice, these constraints are acceptable for surgical pathology reports, and in the test material, $96.7 \%$ of diagnostic summary statements were correctly encoded. The system depends on: positive matching between input phrase and com $\Rightarrow$ puter dictionary. Positive errors would require the use of an incorrect (but dictionary acceptable) phrase by the pathologists. This is very much less likely than incorrect manual dictionary lookup or a transcription error in the recording of a numeric code. If tho diagnosis is correctly dictated but typing errorsw produce spelling mistakes, the record is almost in $-\overrightarrow{0}$ variably rejected by the computer and returned for amendment.

The pilot encoder has now been in daily use in this laboratory for six months. The pathologisto dictates in free English the surgical report which is typed onto the form with the use of a papertape typewriter. At the end of the report the typist re

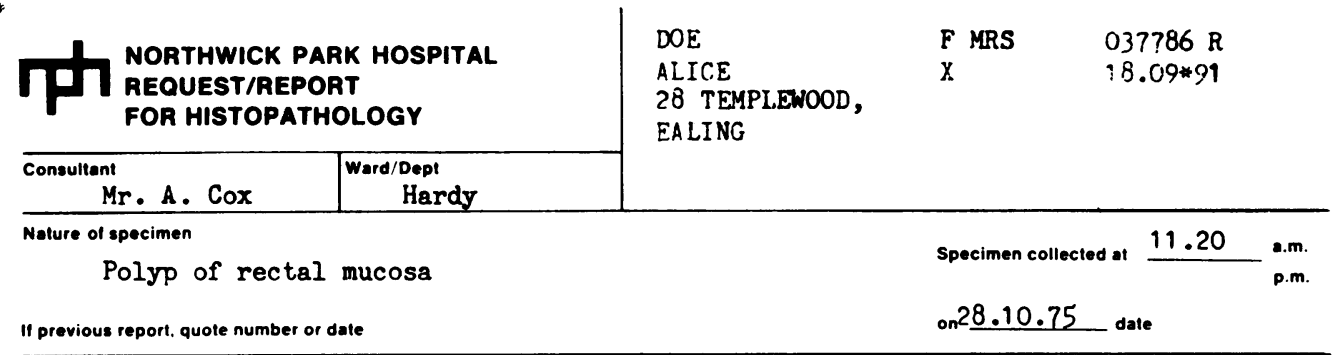

Summary of clinical history

3 months diarrhoea

Rectal polyp seen at $15 \mathrm{~cm}$.

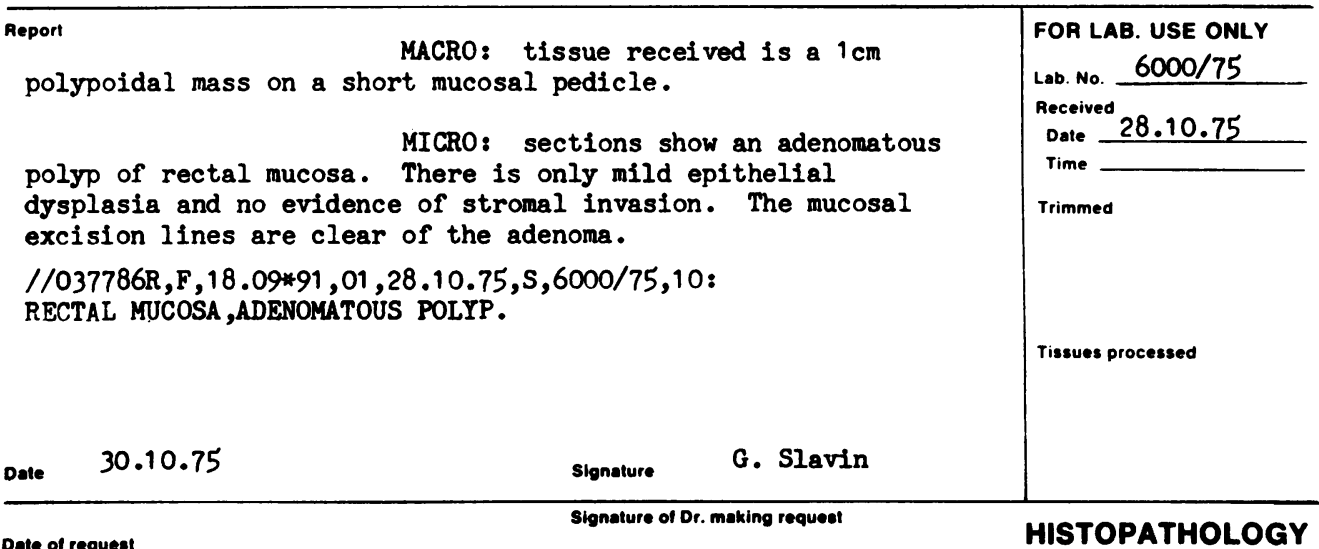

Fig 1 Request/report form showing the conventional report followed by the data for the computer which is typed with the paper-tape punch switched on. The first line starts with two solidi and contains items identifying the patient and specimen which are separated from each other by commas and terminated by a colon. These are (1) hospital unit number, (2) sex, (3) date of birth (an asterisk indicating that the year is in the last century), (4) code for the clinical consultant, (5) date specimen removed, (6) specimen type code (S for surgical pathology), (7) laboratory accession number, and (8) code for reporting pathologist. The second line contains the diagnostic summary in $T, M, E, F$ format with the fields separated from each other by commas and the whole statement terminated by a full stop. 
INPUT 10 LINE AND PHRASES

$11966702 E, F, 18,09499,78,9,5,75,5,2106 / 75,10$, CAECUM
ADENOCARCIINOMA

1/037786R,F,18,09*91,01,28,10,75,S,R000/75,10: RECTAL MUCOSA ADENOMATOUS POLYP

I/F3973,F,.982,8.9,75,5,3973/75,10:

LYMPM MODE

CASEATING GRANIJLOMATOUS INFLAMMATION MYCOBACTERIUM TUBERCULOSIS

I/F2084,.,481,9,5.75,5,2084/75,10:

CUNJUNCTIVE CHRONIC INFLAMHATION

\section{$11964866 \mathrm{~T}, F, 04,06,52,81,9,9,75,5,3907175,10:$ ENDOMETRIUM SECRETORY ENROMETRIUA \\ ENDOCERVIX \\ CHRONIC CERVICITIS}

CODE

OUTPUT PHRASES

76710 CECUM

M8143 ADENOCARCINOMA

16809

M8210

RECTAL MUCOUS memBrane

ADENOMATOUS POLYP

70800

M4470

E1750

59492

LYMPH NODE NOS

INFLAMMATION NECROTIZING GRANULOMATOUS

MYCOBACTERIUM NOS

TUBERCULOSIS NOS
T.* NOT FOUND IN ENCODING DICTIONARY *.*

M4300 INFLAMMATION CHRONIC NOS

T8400 ENDOMETRIUM

M7832 ENDOMETRIUM SECRETORY

T8330 ENDOCERVIX

M4300 INFLAMMATION CHRONIC NOS

Fig 2 Output from the pilot encoding program. The input phrases are on the left, the codes generated in the centre, and the decoded version of the statement on the right.

cords some identity details for the patient and specimen and then the pathologist's summary. This is dictated as one or more diagnoses expressed as SNOP phrases in the required sequence of T, M, E, F (fig 1). During these processes the paper-tape punch is activated to obtain a computer-readable version of what is typed.

We have been agreeably surprised by the success of the pilot encoder, and it has made relatively small demands on both the reporting pathologists and the typing staff. Both pathologist and typist need a period of adjustment to become familiar with the system but this is rapidly induced by reviewing daily the previous day's summaries on a computer printout (fig 2) which indicates the codes generated and any errors.

The number of diagnoses in surgical pathology is limited, and the coding of most specimens requires only a limited vocabulary of SNOP phrases, and any idiosyncrasies of phraseology are quickly learned by the reporting pathologist. We are applying this system to necropsy encoding where the range of diagnoses is wider and where much more reference to the SNOP manual is necessary to obtain exact phrase matching. We think that this may be minimized by the selective use of some of Pratt's analytical rules while retaining the T, M, E, F format. The development of the pilot system to include necropsy diagnoses will be the subject of a further report.

We wish to thank Drs Pratt and Pacak and their colleagues at the National Institutes of Health for access to and details of their encoder. We also wish to thank Mr Kennedy, who has written our computer program, Mrs McHale, who has typed the data, and the Department of Health and Social Security who have provided us with financial support.

\section{References}

College of American Pathologists (1965). Systematised Nomenclature of Pathology. Chicago, Illinois.

Curran, R. C. and Codling, B. (1973). Personal communication.

Dinwoodie, H. P. and Howell, R. W. (1973). Automatic disease coding: the 'fruit-machine' method in general practice. Brit. J. prev. soc. Med., 27, 59-62.

Enlander, D. (1975). Computer processing of medical diagnoses in pathology. Amer. J. clin. Path., 63, 538-544.

Gaynon, P. and Wong, R. L. (1972). A retrieval system for a library of pathology reports, slides and kodachromes. Meth. Inform. Med., 11, 152-162.

Kayser, K. and Höpker, W.-W. (1973). Formal considerations on text analysis in anatomic pathology. Meth. Inform. Med., 12, 143-146.

Pratt, A. W. (1973). Medicine, computers and linguistics. Advanc. Biomed. Engng., 3, 97-140.

Pratt, A. W. and Pacak, M. (1969). Identification and transformation of terminal morphemes in medical English. Meth. Inform. Med., 8, 84-90.

Pratt, A. W. and Thomas, L. B. (1966). An information processing system for pathology data. Path. Ann., 1, 1-21.

Royal College of Pathologists (1975). Systematised Nomenclature of Pathology: A Bench Synopsis.

Smith, J. C. and Melton, J. (1964). Manipulation of autopsy diagnoses by computer technique. J. Amer. med. Ass., 188, 958-962. 